\title{
EVALUASI PELAKSANAAN PEMBIMBINGAN DOSEN PEMBIMBING TERHADAP MAHASISWA PPL FT UNJ
}

\author{
Daryati $^{T}$ \\ ${ }^{1}$ Dosen PTB FT UNJ, daryati_sr@unj.ac.id
}

\begin{abstract}
Abstrak
Tujuan penelitian ini adalah untuk mengevaluasi pelaksanaan bimbingan oleh dosen pembimbing PPL dalam melaksanakan bimbingannya kepada mahasiswa PPL.

Penelitian dilakukan di Fakultas Teknik Universitas Negeri Jakarta dan SMK se-Jakarta, Bogor, Depok, Tangerang, dan Bekasi yang digunakan untuk tempat PPL mahasiswa Fakultas Teknik Universitas Negeri Jakarta. Penelitian ini dilakukan pada semester 096 atau semester genap tahun akademik 2011/2012.

Metode penelitian yang digunakan dalam penelitian ini adalah metode deskriptif. Data diperoleh dengan pengisian angket oleh dosen pembimbing PPL dan mahasiswa PPL serta guru pamong sebagai verifikasi data.

Sebagai populasi dalam penelitian ini adalah dosen-dosen Fakultas Teknik dari semua program studi kependidikan yang membimbing PPL pada semester genap 2011/2012. Sampel dalam penelitian ini adalah 21 dosen pembimbing dari total 41 dosen pembimbing PPL. Untuk verifikasi data penulis mengambil sampel dari mahasiswa peserta PPL FT UNJ sebanyak 69 mahasiswa PPL dan guru pamong sebanyak 47 guru pamong. Semua sampel diambil secara acak (random sampling). Untuk mengetahui pelaksanaan pembimbingan PPL oleh guru pamong dilakukan analisis dengan persentase.

Hasil penelitian ini menunjukkan bahwa mayoritas dosen pembimbing sudah membimbing secara baik. Pembimbingan dilakukan mulai dari saat pembekalan PPL hingga pasca latihan praktik mengajar. Kehadiran dosen pembimbing masih kurang dari yang seharusnya sehingga perlu ditambah.
\end{abstract}

Kata kunci: Evaluasi, Dosen Pembimbing, Pelaksanaan, PPL, UNJ

\section{EVALUATION OF THE IMPLEMENTATION OF SUPERVISION THE MENTORING LECTURER TO STUDENT COLLEGE PPL FT UNJ}

\author{
Daryati $^{\top}$ \\ ${ }^{1}$ Lecturer of PTB FT UNJ, daryatisn@unj.ac.id
}

\begin{abstract}
The purpose of this research is evaluate to the implementation of the guidance from PPL mentoring lecturers in implementation mentoring to PPL student college.

The research was conducted at Faculty of Engineering State University of Jakarta and SMK Jakarta, Bogor, Depok, Tangerang, and Bekasi used to PPL place student college of the Faculty of Engineering State University of Jakarta. The research was conducted on 096 semester or even semester of academic year $2011 / 2012$.

The research method used in this research is descriptive method. Data obtained with filling a questionnaire by the supervisor and the PPL student college with tutor teachers as verifiy the data.
\end{abstract}


As the population in this study are the lecturers of the Faculty of Engineering of the educational courses that guide PPL in the even semester 2011/2012. Sample in this research was 21 mentoring lecturers from the total of 41 PPL mentoring lecturers. For the verify the data the authors take a sample from the student college participating in PPL FT UNJ many as 69 PPL students college and 47 tutor teachers. All samples take at random (random sampling). For the know implementation of PPL mentoring from tutor teachers, analysis conducted by a percentage.

The results of this indicate research that the majority of mentoring lecturers are well guided. Tutoring conducted from the current PPL debriefing after exercise to practice teaching. The presence of mentoring lecturers is still less than it should be so it needs to be added.

Keywords: Evaluation, Mentoring Lecturer, Implementation, PPL, UNJ

\section{Pendahuluan}

Sebagai salah satu lembaga pendidikan, Universitas Negeri Jakarta harus mampu menyediakan tenaga kependidikan yang profesional. Tindak lanjutnya adalah dengan menyelenggarakan program kependidikan yang bertujuan untuk menghasilkan lulusan yang mampu melaksanakan tugas-tugas kependidikan dan keguruan secara mandiri dan kelak setelah selesai akan bekerja sebagai tenaga kependidikan yang profesional.

Untuk mencapai tujuan tersebut diperlukan pengalaman berupa latihan profesional di tempat yang mirip dengan tempat yang kelak para lulusan bertugas. Latihan tersebut disebut Program Pengalaman Lapangan yang selanjutnya disingkat PPL.

Program Pengalaman Lapangan merupakan muara dari seluruh program kependidikan yang telah didapatkan oleh mahasiswa selama di bangku kuliah sehingga PPL dapat diartikan sebagai suatu program yang merupakan ajang pelatihan untuk menerapkan berbagai pengetahuan, sikap dan keterampilan dalam rangka pembentukan guru yang profesional dan handal.

Menurut buku Pedoman PPL bahwa kegiatan PPL diselenggarakan secara bertahap, terpadu dan dalam bentuk orientasi lapangan, pelatihan terbatas, pelatihan terbimbing dan pelatihan mandiri dibawah bimbingan seorang dosen pembimbing dan seorang guru pamong yang memenuhi persyaratan sesuai dengan ketentuan yang telah ditentukan dalam buku Pedoman PPL.

Sebagai tenaga kependidikan yang profesional, lulusan Universitas Negeri Jakarta bidang kependidikan harus memiliki seperangkat kompetensi yang diperlukan oleh seorang guru profesional serta dapat menerapkan dalam penyelenggaraan berbagai program kependidikan baik di sekolah maupun di luar sekolah. Adapun menurut Undang-Undang No.14 tahun 2005 tentang guru dan dosen bahwa kompetensi yang harus dimiliki oleh seorang guru meliputi: kompetensi pedagogik, kompetensi kepribadian, kompetensi sosial, dan kompetensi profesional.

Pada pelaksanaan PPL di lapangan, kegiatan yang dilaksanakan selama berlangsungnya PPL adalah (1) kegiatan observasi; (2) kegiatan pelatihan keterampilan mengajar dan tugas keguruan lainnya secara terbimbing; (3) kegiatan pelatihan mengajar dan tugas keguruan lainnya secara mandiri dan (4) ujian praktik mengajar.

Pada kegiatan orientasi dan observasi dimaksudkan agar mahasiswa sebagai peserta PPL mengenal lingkungan sekolah yang digunakan untuk tempat praktik. 
Pengenalan lingkungan ini meliputi observasi pengenalan lapangan dan observasi ketrampilan dasar mengajar dan tugas non mengajar.

Dalam kegiatan observasi

keterampilan dasar mengajar dan tugas non mengajar, mahasiswa peserta PPL mengamati bagaimana guru pamong pada saat mengajar terutama dalam menerapkan delapan kompetensi dasar mengajarnya. Ada delapan kompetensi dasar mengajar diantaranya:

(1) keterampilan bertanya,

(2) keterampilan memberikan penguatan,

(3) keterampilan mengadakan variasi,

(4) keterampilan menjelaskan,

(5) keterampilan membuka dan menutup pelajaran,

(6) keterampilan membimbing diksusi kelompok kecil,

(7) keterampilan mengelola kelas, dan

(8) keterampilan mengajar kelompok kecil dan perseorangan.

Untuk memudahkan penyelenggaraan Program Pengalaman Lapangan (PPL), supervisi dilakukan oleh dosen pembimbing dan guru pamong. Supervisor akan sangat membantu mahasiswa calon guru dalam meningkatkan kemampuan mengajar dengan mengobservasi, merefleksi, dan menganalisis tingkah laku mengajarnya.

Meskipun supervisi itu sangat penting dalam upaya peningkatan kemampuan profesional calon guru, namun seringkali mahasiswa sebagai calon guru kurang menyukai supervisi tersebut, yang pada umumnya bersumber dari gaya supervisi. Gaya supervisi yang tradisional tersebut tidak memadai untuk menumbuhkan sikap dan kemampuan profesional calon guru. Morris Cogan, Robert Goldammer, dan kawan-kawannya di Harvard School of Education, mengembangkan suatu pendekatan atau gaya baru dalam supervisi. Pendekatan atau gaya supervisi tersebut diberi nama Supervisi Klinis (Clinical Supervition), dengan penekanan pada hubungan tatap muka (fase to fase) antara supervisor dengan yang dibimbing (calon guru).
Menurut Taufik Sabirin (2009), supervisi klinis adalah suatu proses bimbingan yang bertujuan untuk membantu pengembangan profesional guru dalam pelaksanaan proses pembelajaran. Richad Waller dalam La Sulo (1983) mengatakan: "Clinical supervisition may be defined as supervition focused upon the inprovement of instruction by means of sistematic cycles of planning, observation and intensive intelectual analysis of actual teaching performance in the interest of rational modification". Pendapat Richard di atas mengenai supervisi klinis memfokuskan pada upaya perbaikan proses pembelajaran yang dilakukan bersiklus. Perbaikan dilaksanakan berkelanjutan sampai kondisi yang diinginkan tercapai.

Menurut Taufik Sabirin (2009), instrumen supervisi klinis terdiri dari empat aspek yakni: aspek kependidikan, akademik, pengelolaan kelas dan interaksi dengan siswa dalam proses pembelajaran.

Pelaksanaan supervisi klinis dalam Program Pengalaman Lapangan (PPL) direalisasikan dengan membentuk beberapa tim yaitu, tim dari pihak sekolah tempat calon guru berpraktik (guru pamong, koordinator guru pamong atau kepala sekolah), tim dari unit UPT PPL (koord. PPL) dan tim dari jurusan atau dari program studi Dosen Pembimbing. Tim ini dibekali panduan khusus untuk memberikan bekal keterampilan kepada calon guru dan tim ini bertanggung jawab kepada Dekan.

Supervisi untuk latihan praktik mengajar diberikan oleh guru pamong bersama dosen pembimbing. Pelaksanaannya sebagai berikut:

a. Supervisi awal diberikan kepada mahasiswa PPL untuk menentukan isi materi pelajaran, model, metodik khusus pembelajaran, teknik khusus pembelajaran serta penyusunan Rencana Program Pembelajaran.

b. Pengamatan latihan praktik mengajar oleh pembimbing guna mencatat data mengenai perkembangan keterampilan mengajar mahasiswa PPL.

c. Supervisi pasca latihan praktik mengajar, yaitu untuk memberikan data 
hasil pengamatan perkembangan kemampuan dan keterampilan mahasiswa pada saat latihan.

Kegiatan PPL perlu mendapat perhatian yang sungguh-sungguh secara terpadu, terarah, dan terbimbing dari berbagai unsur yang terkait. Usaha untuk memberikan bimbingan kepada mahasiswa calon guru dalam kegiatan PPL merupakan sesuatu yang mutlak harus dilakukan oleh pembimbing (dosen pembimbing dan guru pamong). Salah satu komponen penting dalam proses bimbingan tersebut adalah Supervisi Klinis. Hal ini sangat penting dilakukan mengingat mahasiswa sebagai calon guru merupakan orang yang harus dipersiapkan untuk menjadi guru. Dalam pelaksanaannya supervisi klinis pembimbing memberikan bimbingan kepada mahasiswa sebagai calon guru sesuai dengan kebutuhan yang bersangkutan sehingga mahasiswa calon guru akan mampu menemukan kelemahan yang ada pada dirinya dan akan mampu untuk meningkatkan dirinya melalui analisis bersama dalam kegiatan supervisi klinis. Berdasarkan uraian diatas, penelitian ini akan melihat sejauh manakah pelaksanaan bimbingan atau supervisi klinis dosen pembimbing pada mahasiswa PPL.

\section{Metode Penelitian}

Tujuan penelitian secara operasional adalah untuk melakukan evaluasi pelaksanaan bimbingan dari guru pamong agar dapat melaksanakan bimbingan kepada mahasiswa PPL sesuai ketentuan dan kelak mahasiswa yang dimbimbing dapat menjadi guru yang profesional.

Penelitian ini dilakukan di SMK-SMK se Jakarta, Bogor, Depok, Tangerang dan Bekasi yang digunakan sebagai tempat PPL mahasiswa Fakultas Teknik Universitas Negeri Jakarta. Penelitian ini dilakukan pada semester 096 atau semester genap tahun akademik 2011/2012.

Metode yang digunakan dalam penelitian ini adalah metode deskriptif. Data yang didapat dari pengisian angket oleh dosen pembimbing yang terdiri dari dosendosen FT UNJ yang ditunjuk oleh Dekan
FT UNJ sebagai dosen pembimbing mahasiswa PPL FT UNJ di semester 096 tahun akademik 2011/2012. Sedangkan untuk verifikasi data, peneliti juga menyebarkan angket kepada mahasiswa PPL dan guru pamong di semester yang sama. Dengan pengisian angket oleh guru pamong dan mahasiswa PPL, maka dapat digunakan untuk memverifikasi data yang telah didapat dari dosen pembimbing.

\section{Populasi Penelitian}

Populasi dalam penelitian ini adalah dosen Fakultas Teknik UNJ yang bertugas sebagai dosen pembimbing dalam pelaksanan PPL FT UNJ semester genap 2011/2012. Sebagaimana telah ditentukan dalam Buku Pedoman PPL FT UNJ bahwa yang menjadi dosen pembimbing mahasiswa PPL FT UNJ dengan sejumlah persyaratan yang ditentukan dalam Buku Pedoman PPL FT UNJ.

\section{Sampel Penelitian}

Sampel yang digunakan dalam penelitian ini adalah dosen Fakultas Teknik yang bertugas menjadi dosen pembimbing PPL di semester 096 tahun akademik 2011/2012. Banyaknya dosen pembimbing adalah 41 orang dan yang menjadi sample sebanyak 21 orang. Semua sampel diambil secara acak (random sampling). Untuk verifikasi data penulis mengambil sebanyak 69 mahasiswa dari mahasiswa peserta PPLFT-UNJ yang berjumlah 239 mahasiswa. Penulis juga mengambil data untuk verifikasi dari guru pamong sebanyak 47 orang dari total guru pamong 148 orang.

\section{Hasil dan Pembahasan}

\section{Hasil Penelitian}

Dari angket tentang pelaksanaan pembimbingan PPL oleh dosen pembimbing terhadap mahasiswa peserta PPL yang telah dilakukan, hasilnya adalah sebagai berikut: 
Tabel 1. Persentase Pelaksanaan Bimbingan PPL oleh Dosen Pembimbing

\begin{tabular}{|c|c|c|c|}
\hline \multirow{2}{*}{ No. } & \multirow{2}{*}{ Pertanyaan } & \multicolumn{2}{|c|}{ Jawaban } \\
\hline & & $\mathrm{Ya}$ & Tidak \\
\hline & $\begin{array}{l}\text { Mulai membimbing pada saat kegiatan pembekalan PPL } \\
\text { khususnya Micro teaching }\end{array}$ & $66,7 \%$ & $33,3 \%$ \\
\hline 2. & Datang pada saat pelepasan PPL & $71,4 \%$ & $28,6 \%$ \\
\hline 3. & Mengantarkan mhs PPL ke sekolah tempat PPL & $100 \%$ & $0 \%$ \\
\hline 4. & $\begin{array}{l}\text { Mengikuti kegiatan penyusunan program kegiatan PPL di } \\
\text { sekolah }\end{array}$ & $85,7 \%$ & $14,3 \%$ \\
\hline 5. & Membimbing penyusunan RPP & $66,7 \%$ & $33,3 \%$ \\
\hline 6. & Memonitor kedalam kelas pada saat mhs PPL mengajar & $76,2 \%$ & $23,8 \%$ \\
\hline 7. & Memberi motivasi kepada mhs PPL & $85,7 \%$ & $14,3 \%$ \\
\hline 8. & Memonitor RPP yang sudah ditampilkan & $47,6 \%$ & $53,4 \%$ \\
\hline & $\begin{array}{l}\text { Memberikan informasi tentang hasil pengamatan pada saat } \\
\text { mhs PPL mengajar }\end{array}$ & $76,2 \%$ & $23,8 \%$ \\
\hline 10. & Memberikan umpan balik saat memonitor mhs & $71,4 \%$ & $28,6 \%$ \\
\hline & $\begin{array}{l}\text { Turut menyelesaikan masalah yang terjadi antara sekolah dan } \\
\text { mahasiswa }\end{array}$ & $66,7 \%$ & $33,3 \%$ \\
\hline 12. & Bersama guru pamong menentukan waktu ujian & $85,7 \%$ & $14,3 \%$ \\
\hline
\end{tabular}

Untuk keperluan verifikasi data, peneliti juga menyebarkan angket kepada mahasiswa PPL dan guru pamong.

Tabel 2. Persentase Verifikasi Data oleh Mahasiswa PPL

\begin{tabular}{lllc}
\hline \multirow{2}{*}{ No. } & \multicolumn{1}{c}{ Pertanyaan } & \multicolumn{2}{c}{ Jawaban } \\
\cline { 2 - 4 } 1. & $\begin{array}{l}\text { Pada saat pembekalan khususnya kegiatan microteaching dibimbing } \\
\text { dosen pembimbing. }\end{array}$ & $97,1 \%$ & $2,9 \%$ \\
\hline 2. & Pada saat pelepasan PPL dosen pembimbing hadir & $98,5 \%$ & $1,5 \%$ \\
\hline 3. & Pertama datang ke sekolah diantar dosen pembimbing & $87,0 \%$ & $13,0 \%$ \\
\hline 4. & $\begin{array}{l}\text { Dosen pembimbing memeriksa RPP yang dibuat oleh mahasiswa } \\
\text { sebelum ditampilkan }\end{array}$ & $66,7 \%$ & $33,3 \%$ \\
\hline 5. & $\begin{array}{l}\text { Setelah RPP dibuat selanjutnya dosen pembimbing mengharuskan } \\
\text { mahasiswa membuat media pembelajarannya. }\end{array}$ & $65,2 \%$ & $34,8 \%$ \\
\hline 6. & $\begin{array}{l}\text { Dosen pembimbing memeriksa media pembelajaran yang dibuat } \\
\text { mahasiswa. }\end{array}$ & $49,3 \%$ & $50,7 \%$ \\
\hline 7. & $\begin{array}{l}\text { Dosen pembimbing memeriksa media pembelajaran yang dibuat } \\
\text { mahasiswa. }\end{array}$ & $84,1 \%$ & $15,9 \%$ \\
\hline 8. & $\begin{array}{l}\text { Dosen pembimbing memonitor ke dalam kelas saat mahasiswa } \\
\text { mengajar }\end{array}$ & $84,1 \%$ & $15,9 \%$ \\
\hline 9. & Jumlah kehadiran dosen pembimbing & $\ldots \ldots . . \mathrm{X}$ & \\
\hline
\end{tabular}


Tabel 3. Kehadiran Dosen Pembimbing oleh Mahasiswa PPL

\begin{tabular}{cc}
\hline \multicolumn{2}{c}{ Kehadiran Dosen Pembimbing } \\
\hline Jumlah Kehadiran & Jumlah Responden \\
\hline 0 & 20 \\
\hline 1 & 7 \\
\hline 3 & 4 \\
\hline 4 & 14 \\
\hline 5 & 8 \\
\hline 6 & 3 \\
\hline 8 & 4 \\
\hline 9 & 2 \\
\hline 12 & 2 \\
\hline $\begin{array}{c}13 \text { (maksimal } \\
\text { kehadiran) }\end{array}$ & 5 \\
\hline
\end{tabular}

Tabel 4. Persentase Kehadiran Dosen

\begin{tabular}{ccc}
\hline Interval & Frekuensi & Persentase $(\%)$ \\
\hline $0-3$ kali & 31 & 44,9 \\
\hline $4-7$ kali & 25 & 36,2 \\
\hline $8-11$ kali & 6 & 8,7 \\
\hline $12-15$ kali & 7 & 10,2 \\
\hline
\end{tabular}

Tabel 5. Persentase Verifikasi Data oleh Guru Pamong

\begin{tabular}{|c|c|c|c|}
\hline \multirow{2}{*}{ No. } & \multirow{2}{*}{ Pertanyaan } & \multicolumn{2}{|c|}{ Jawaban } \\
\hline & & $\mathrm{Ya}$ & Tidak \\
\hline 1. & $\begin{array}{l}\text { Dosen pembimbing memeriksa RPP yang dibuat oleh } \\
\text { mahasiswa sebelum ditampilkan }\end{array}$ & $68,1 \%$ & $31,9 \%$ \\
\hline 2. & $\begin{array}{l}\text { Setelah RPP dibuat selanjutnya dosen pembimbing } \\
\text { mengharuskan mahasiswa membuat media pembelajarannya. }\end{array}$ & $63,8 \%$ & $36,2 \%$ \\
\hline 3. & $\begin{array}{l}\text { Dosen pembimbing memeriksa media pembelajaran yang } \\
\text { dibuat mahasiswa. }\end{array}$ & $53,2 \%$ & $46,8 \%$ \\
\hline 4. & $\begin{array}{l}\text { Dosen Pembimbing memonitor ke dalam kelas saat mahasiswa } \\
\text { PPL mengajar }\end{array}$ & $57,4 \%$ & $42,6 \%$ \\
\hline 5. & Bersama dosen pembimbing menentukan waktu ujian PPL & $87,2 \%$ & $12,8 \%$ \\
\hline
\end{tabular}

\section{Pembahasan Penelitian}

Pembahasan dari hasil penelitian yang didapat dari sejumlah angket yang telah diisi oleh dosen pembimbing, diantaranya:

1) Mulai membimbing pada saat kegiatan pembekalan PPL khususnya micro teaching

Responden yang menjawab ya sebesar $66,7 \%$ dan tidak sebesar 33,3\%. Hal ini juga diperkuat dengan angket mahasiswa PPL sebagai data verifikasi, bahwa hampir keseluruhan dosen pembimbing $\quad(97,1 \%) \quad$ sudah membimbing dari kegiatan micro teaching saat pembekalan. Dengan dilibatkannya dosen pembimbing pada saat pembekalan PPL diharapkan dapat memotivasi supervisor melaksanakan fungsi dan tugasnya.

2) Datang pada saat pelepasan PPL

Responden yang menjawab ya sebesar $71,4 \%$ dan tidak sebesar $28,6 \%$. Hal ini diperkuat dengan angket mahasiswa PPL sebagai data verifikasi, bahwa hampir keseluruhan dosen pembimbing $(98,5 \%)$ hadir pada saat pelepasan PPL. 
3) Mengantarkan mahasiswa PPL ke sekolah tempat PPL

Responden yang menjawab ya sebesar $100 \%$ dan tidak sebesar $0 \%$. Dari angket yang diberikan kepada mahasiswa PPL sebagai data verifikasi, bahwa masih ada dosen pembimbing yang tidak mengantarkan mahasiswanya saat pertama kali datang ke sekolah.

4) Mengikuti kegiatan penyusunan program kegiatan PPL di sekolah

Responden yang menjawab ya sebesar $85,7 \%$ dan tidak sebesar $14,3 \%$. Hal ini berarti bahwa sebagian besar dosen pembimbing mengikuti kegiatan penyusunan program kegiatan PPL.

5) Membimbing penyusunan RPP

Responden yang menjawab ya sebesar $66,7 \%$ dan tidak sebesar $33,3 \%$. Dari angket yang diberikan kepada mahasiswa PPL sebagai data verifikasi, bahwa masih ada dosen pembimbing $(33,3 \%)$ yang tidak membimbing mahasiswa menyusun RPP. Apabila dosen pembimbing membimbing saat mahasiswa menyusun RPP, maka dosen pembimbing akan mengetahui RPP yang diberlakukan di sekolah tersebut.

6) Memonitor ke dalam kelas pada saat mahasiswa mengajar

Responden yang menjawab ya sebesar $76,2 \%$ dan tidak sebesar $23,8 \%$. Berdasarkan angket dari mahasiswa PPL sebagai data verifikasi, masih ada dosen pembimbing yang tidak memonitor ke dalam kelas (15,9\%). Dengan adanya dosen pembimbing yang membantu mengobservasi, merefleksi, dan menganalisis tingkah laku mengajar mahasiswa PPL bimbingannya, maka akan dapat meningkatkan kemampuan mengajar dari mahasiswa yang dibimbingnya.

7) Memberi motivasi kepada mahasiswa PPL

Responden yang menjawab ya sebesar $85,7 \%$ dan tidak sebesar $14,3 \%$. Hal ini diartikan bahwa sebagian besar dosen pembimbing telah memberikan motivasi kepada mahasiswa PPL.
Memberikan motivasi mengajar kepada mahasiswa PPL bertujuan untuk menggerakkan kemauan mengajar mahasiswa PPL agar dapat tampil secara profesional dalam menjalankan tugasnya sebagai guru.

8) Memonitor RPP yang sudah ditampilkan

Responden yang menjawab ya sebesar 47,6\% dan tidak sebesar 53,3\%. Kenyataan ini sangat disayangkan karena seharusnya supervisi yang diberikan kepada mahasiswa PPL oleh dosen pembimbing maupun guru pamong dapat memberikan saran terhadap RPP sesudah ditampilkan mahasiswa saat latihan mengajar.

Dari angket yang diberikan kepada guru pamong sebagai data verifikasi, bahwa semua guru pamong $(100 \%)$ memonitor RPP yang sudah ditampilkan oleh mahasiswa PPL. Sehingga dapat diketahui berapa kali mahasiswa PPL sudah tampil dan mengajar di depan kelas.

9) Memberikan informasi kepada mahasiswa tentang hasil pengamatan pada saat mengajar

Responden yang menjawab ya sebesar 76,2\% dan tidak sebesar 23,8\%. Pengamatan dilakukan agar dosen pembimbing mengetahui perkembangan kemampuan mahasiswa pada saat latihan mengajar untuk selanjutnya didiskusikan mengenai kelebihan dan kekurangan dalam mengajar.

10) Memberikan umpan balik saat memonitor mahasiswa

Responden yang menjawab ya sebesar 71,4\% dan tidak sebesar 28,6\%. Dosen pembimbing sebagai pengamat menyampaikan data mengenai tampilan mengajar, selanjutnya data tersebut didiskusikan agar pada latihan mengajar berikutnya dapat lebih baik lagi.

11) Turut menyelesaikan masalah yang terjadi antara sekolah dan mahasiswa

Responden yang menjawab ya sebesar $66,7 \%$ dan tidak sebesar 33\%. dengan dosen pembimbing turun 
tangan dan berunding maka permasalahan dapat diselesaikan. Ada sejumlah dosen pembimbing (33,3\%) yang tidak ikut menyelesaikan masalah antara sekolah dengan mahasiswa PPL, hal ini mohon diselesaikan oleh pihak Fakultas Teknik.

12) Bersama guru pamong menentukan waktu ujian

Responden yang menjawab ya sebesar $85,7 \%$ dan tidak sebesar $14,3 \%$. Dari data angket yang diberikan kepada guru pamong sebagai data verifikasi, bahwa semua dosen pembimbing $(100 \%)$ bersama guru pamong menentukan waktu ujian PPL.

13) Tentang kehadiran dosen pembimbing

Kehadiran dosen pembimbing ke sekolah adalah sebanyak 44,9\% hadir (maksimum 3 kali) dan sebagian besar dosen pembimbing hadir sebanyak 0 s/d 7 kali. Hanya 10,2\% dosen pembimbing yang hadir antara $8 \mathrm{~s} / \mathrm{d} 16$ kali. Data ini sangat memprihatinkan dan tidak sesuai dengan yang diharapkan. Peraturan yang telah ditetapkan dalam Buku Pedoman PPLFT-UNJ bahwa kehadiran dosen pembimbing di sekolah tempat PPL antara 8 s/d 16 kali. Dengan kenyataan ini akan menjadi perhatian dari pihak Fakultas Teknik.

\section{Kesimpulan dan Saran}

\section{Kesimpulan}

Berdasarkan hasil penelitian maka dapat ditarik kesimpulan sebgai berikut:

1. Sebagian besar dosen pembimbing sudah membimbing secara baik pada saat mahasiswa mengikuti pembekalan maupun pada saat melaksanakan PPL di sekolah. Dosen pembimbing juga telah melaksanakan supervisi klinisnya pada saat mahasiswa membuat perangkat pembelajaran seperti: membuat RPP, menyusun materi pembelajaran, dan membuat media pembelajaran.
2. Pada saat mahasiswa mengajar, dosen pembimbing tetap melaksanakan supervisi klinisnya sehingga mengetahui betul tahapan perkembangan kemampuan mahasiswa PPL dalam mengajar.

3. Kehadiran dosen pembimbing yang masih sangat kurang artinya belum sesuai dengan ketentuan yang berlaku yaitu antara 8 sampai 16 kali.

\section{Saran}

1. Dosen pembimbing yang belum membimbing dengan baik pada saat mahasiswa PPL mempersiapkan perangkat pembelajarannya, agar melaksanakan supervisinya karena dengan kurikulum KTSP memungkinkan beragamnya bentuk RPP.

2. Semua dosen pembimbing agar memonitor ke dalam kelas pada saat mahasiswa PPL latihan mengajar. Dengan begitu dosen pembimbing dapat mengobservasi, merefleksi, dan menganalisis tingkah laku mengajar mahasiswa PPL dan dapat meningkatkan kemampuan mengajarnya hingga lebih baik lagi.

3. Sebelum menentukan waktu ujian, agar dosen pembimbing melihat secara jeli kemampuan mahasiswa PPL dalam mengajar sehingga diharapkan pada saat ujian mahasiswa betul-betul sudah siap dan dapat memperoleh hasil yang maksimum. 


\section{Daftar Pustaka}

--------. 2006. Undang Undang Republik Indonesia No.14 Tentang Guru dan Dosen. Jakarta: CV Eka Jaya.

Lembaga Akta Mengajar. 2004. Pedoman Pelaksanaan Program Pengalaman Lapangan. Jakarta: Universitas Negeri Jakarta.

Solo Lipo La Sulo, dkk. 1995. Supervisi Klinis. Jakarta: Departmen Pendidikan dan Kebudayan Dirjen Pendidikan Tinggi.

Unit Pelayanan Teknis PPL UNJ. 2004. Pedoman Pelaksanaan Program Pengalaman Lapangan. Jakarta: Universitas Negeri Jakarta. 